\title{
Essential oils for the treatment of dust mites
}

\author{
Qing-ming $\mathrm{Fu}^{1,4}$, Bin Zeng ${ }^{4}$, Qing-yue Xiao ${ }^{4}$, Bin-sheng $\mathrm{He}^{1,2, *}$, Chun-xia Huang ${ }^{3,4^{*}}$, Mei-hua Bao ${ }^{1,3,4^{*}}$ \\ ${ }^{1}$ Academician Working Station, ${ }^{2}$ The First Affiliated Hospital, ${ }^{3}$ Science Research Center, ${ }^{4}$ School of Stomatology, Changsha Medical \\ University, Changsha, 410219, China.
}

\begin{abstract}
House mites, including D. pteronyssinus and D. farina, are common causes of allergic diseases, such as asthma, atopic dermatitis, eczema, conjunctivitis and perennial rhinitis in susceptible patients. Conventional acaricides, such as benzyl benzoate, bifenthrin, chlorpyrifos are effective chemicals in treating mites. However, they are usually with high drug resistance and high adverse effects on environment, human health, and non-target organisms. Recently, essential oils from different plants were found to be safe and effective alternatives for killing different types of mites. The present review summarized the essential oils from different plants. The crude essential oils from Melissa officinalis, S.lavandulifolia oil, cade oil, P. cattleianum, Patchouli oil, Horseradish oil, C. cassia, P. cablin, Manuka oil, Clove Bud oil, and the pure essential oils, such as eugenol, caryophyllene, and camphor might be good candidates for the dust mites. Further studies on biological mechanisms of the acaricidal effects of these active essential oils, and the structure-activity relationships are needed to make the functions of these drugs more clear.
\end{abstract}

\section{Introduction}

Mites are tiny arthropods belonging to the class of arachnids and the subclass of acari. They are spread across a wide range of habitats. At least 45,000 different species of mites have been described. Some of these mites damage food, cause skin irritation, itchiness and severe bacterial infections.

House mites, including D. pteronyssinus and $D$. farina, are common causes of allergic diseases, such as asthma, atopic dermatitis, eczema, conjunctivitis and perennial rhinitis in susceptible patients [1,2]. $D$. pteronyssinus and $D$. farina are both pyroglyph mites, made up of $60-90 \%$ domestic mites.

Conventional acaricides, such as benzyl benzoate, bifenthrin, chlorpyrifos, pirimipho-methyl and pyrethroids, are effective chemicals in treating mites $[3,4]$. However, they are usually with high drug resistance and high adverse effects on environment, human health, and non-target organisms [4,5]. Recently, essential oils from different plants were found to be safe and effective alternatives for killing different types of mites (Table 1).

\section{Crude essential oils for dust mites}

Pineapple balm, patchouli, horseradish and clove are rich in essential oil. The essential oil from Melissa officinalis, a plant cultivated in France, Ireland, and Serbia, showed high activity on killing both $D$. farina and $D$. pteronyssinus. The $\mathrm{LD}_{50}$ for $D$. farina and $D$. pteronyssinus was 3.91 and $3.53 \mu \mathrm{g} / \mathrm{cm}^{2}$, respectively, representing approximately four to five folds of DEET, a negative control. The patchouli oil extracted from Pogostemon cablin killed the $D$. farina with the $\mathrm{LD}_{50}$ of $6.11 \mu \mathrm{g} / \mathrm{cm}^{2}$, which was 9.58 times of dibutyl phthalate (DBP) $\left(58.52 \mu \mathrm{g} / \mathrm{cm}^{2}\right)$ [6]. Horseradish oil extracted from Armouracia rusticana consisted of different types of isothiocyanates. In a contact plus fumigant mortality bioassay, the horseradish oil $\left(\mathrm{LD}_{50}: 1.54 \mu \mathrm{g} / \mathrm{cm}^{2}\right)$ was more potent compared to DBP $(24.49 \mu \mathrm{g} / \mathrm{cm} 2)$ on killing $D$. farina [7]. The Clove bud oil killed D. farina and $D$. pteronyssinus with the $\mathrm{LD}_{50}$ of $5.91 \mu \mathrm{g} / \mathrm{cm}^{2}$ and 7.86 $\mu \mathrm{g} / \mathrm{cm}^{2}$, respectively, in the contact toxicity bioassay[8]. In addition, Melissa officinalis oil changed the colour of the mites from colorless to golden brown, indicating the acaricide potential of the oil [9].

The essential oils of $P$. cattleianum and Leptospermum scoparium also demonstrated strong acaricide activity. The acaricidal activity of $P$. cattleianum oil was significant when examined by fumigant or contact toxicity bioassays. The $\mathrm{LD}_{50}$ for P.cattleianum oil on D.farina and D.pteronyssinus was 2.44 and $2.40 \mu \mathrm{g} / \mathrm{cm}^{2}$, respectively, which was 8.79 and 12.92 times as active as DEET [10]. Mamuka oil extracted from Ease Cape Mamuka killed D. farina, $D$. pteronyssinus and T. putrescentiae at $\mathrm{LD}_{50}$ of $0.54,0.67$ and $1.12 \mu \mathrm{g} / \mathrm{cm}^{2}$, respectively [11].

Other extractions of essential oils from S.lavandulifolia, S.barbata and A.koreana were also active miticides. They were more powerful acaricids than benzyl benzoate, a traditional chemical drug [12-14]. The S.lavandulifolia oil, S.barbata oil, and A.koreana oil killed D.farina with $\mathrm{LD}_{50}$ of $3.18,2.55$, and $3.53 \mu \mathrm{g} / \mathrm{cm}^{2}$; killed D.pteronyssinus with $\mathrm{LD}_{50}$ of $3.15,2.5$, $4.15 \mu \mathrm{g} / \mathrm{cm}^{2}$; killed T.putrescentiae with $\mathrm{LD}_{50}$ of 4.93 ,

\footnotetext{
*Corresponding author: mhbao78@163.com (Mei-hua Bao); 69661945@qq.com (Bin-sheng He); 19237798@qq.com (Chun-xia Huang)
} 
$5.00,6.27 \mu \mathrm{g} / \mathrm{cm}^{2}$. Whereas Cade oil, Hiba oil, Basil oil, Asarum sieboldii Miq oil and C.obtusa Leaf oil were found without evident acracial activity [15-19].

The Traditional Chinese Medicine (TCM) was considered to be the source of environmentally acceptable and alternative commercial acaricides. The acaricidal activity of petroleum ether, ethyl acetate, and methanol extracts from 22 kinds of TCM was screened. The petroleum ether extract of C. cassia, E. caryophyllata, and $\mathrm{P}$. cablin were with highest activities (4.6, 5.0 and $6.0 \mu \mathrm{g} / \mathrm{cm}^{2}$ respectively, $24 \mathrm{~h}, \mathrm{LD}_{50}$ ) than the extracts of ethyl acetate and methanol [20].

\section{Essential oil compounds for dust mites}

Besides the crude essential oils from different plants, many other active essential oil components or compounds were demonstrated to be effective on dust mites (Table 2).

\subsection{Eugenol and its congeners}

Eugenol is an acaricidal constituents of cade oil, Asarum sieboldii Miquel oil, and Clove bud oil. Eugenol and its congeners (acetyleugenol, isoeugenol, and methyleugenol) are potent acaricides against different mite species. Previous studies indicated the order of lethal effect against $D$. farina was methyleugenol $\left(\mathrm{LD}_{50}\right.$ : 0.94-5.82 $\left.\mu \mathrm{g} / \mathrm{cm}^{2}\right)>$ eugenol $\left(\mathrm{LD}_{50}: 5.47-12.52 \mu \mathrm{g} / \mathrm{cm}^{2}\right)>$ isoeugenol $\left(\mathrm{LD}_{50}: 5.17-36.10 \mu \mathrm{g} / \mathrm{cm}^{2}\right)>$ acetyleugenol $\left(\mathrm{LD}_{50}: 14.16 \mu \mathrm{g} / \mathrm{cm}^{2}\right)$. Among eugenol and its congeners, methyleugenol was with the highest toxicity, which was similar to that of benzyl benzoate $[17,18]$. The lipophilicity of eugenol and its congeners may responsible for their difference of acaricidal acitivities $[8,15]$.

\subsection{Caryophyllenes}

$\alpha$-caryophyllene, $\beta$-caryophyllene, and caryophyllene oxide were found in the components of many essential oils, such as Psidium cattleianum, Melissa officinalis, Basil oil, Clove oil, and Cade oil. Previous studies indicated the neuroprotective, anti-inflammation, and anti-oxidant effects of these essential oils. However, the acaricidal activity of caryophyllene and its derivatives were demonstrated only recently.

Based on the $\mathrm{LD}_{50}$ value estimation against $D$. farina and $D$. pteronyssinus by fumigant method, $\beta$ caryophyllene oxide was the most potent compound $\left(\mathrm{LD}_{50}\right.$ of $1.36 \mu \mathrm{g} / \mathrm{cm}^{2}$ for $D$. farina and $1.36 \mu \mathrm{g} / \mathrm{cm}^{2}$ for D. pteronyssinus), followed by $\alpha$-caryophyllene $\left(\mathrm{LD}_{50}\right.$ of $1.75 \mu \mathrm{g} / \mathrm{cm}^{2}$ for $D$. farina and $9.96 \mu \mathrm{g} / \mathrm{cm}^{2}$ for $D$. pteronyssinus), and $\beta$-caryophyllene $\left(\mathrm{LD}_{50}\right.$ of $3.13 \mu \mathrm{g} / \mathrm{cm}^{2}$ for $D$. farina and $3.58 \mu \mathrm{g} / \mathrm{cm}^{2}$ for $D$. pteronyssinus) [10]. The contact method also indicated the same order of acaricidal potency for $\beta$-caryophyllene oxide, $\alpha$-caryophyllene and $\beta$-caryophyllene [10].

Other studies also discovered good anti-mites effect of $\beta$-caryophyllene with activities of more than 2 folds of
DEET or benzyl benzoate for D. farina, and more than 1.8 folds for $D$. pteronyssinus $[9,12]$. However, some studies didn't find the acaricidal effects for $\beta$ caryophyllene or caryophyllene oxide $[15,17,21]$. This might due to the difference of method used in the evaluation. For example, when the fabric-circle contact bioassay was used, no effects were found for caryophyllene [15,21].

\subsection{Linalool (+/-)}

Linalool is a widely used terpene found in many plant species, such as Salvia Lavandulifolia, and basils. Linalool is used as an important ingredient in shampoos, soaps, and detergents. Studies also demonstrated its antiinflammation, sedation, anti-anxiety effects. Linalool was reported to be an effective killer of dust mites. The acaricidal activities of linalool on $D$. farina and $D$. pteronyssinus were better than benzyl benzoate (1.83 folds and 2.04 folds, respectively) [12]. But less than DEET or DBP [17,21].

\subsection{Camphor and camphene}

Camphor and camphene are important aromatic ingredient of the wood and bark of the camphor tree. They are used as mild topical analgesic and insect repellent.

The acaricidal activity of camphor was detected by several studies. It killed $D$. farina, $D$. pteronyssinus, and T. putrescentiae effectively ( $\mathrm{LD}_{50}$ of $3.41 \mu \mathrm{g} / \mathrm{cm}^{2}, 3.25$ $\mu \mathrm{g} / \mathrm{cm}^{2}$, and $5.10 \mu \mathrm{g} / \mathrm{cm}^{2}$ respectively, by contact bioassay), which was better than benzyl benzoate [12], similar to DEET $[15,17,21,22]$. No acaricidal activity was found for camphene[12].

\subsection{Terpinen-4-ol and terpineol}

Terpinen-4-ol is the major constituent and active ingredient of tea tree oil used for demodex. Besides tea tree oil, the terpinen-4-ol also exists in other plants, such as Juniperus communis, and hiba oil. A moderate activity of terpinen-4-ol against dust mites was found in several studies. The $\mathrm{LD}_{50}$ of terpinen-4-ol on $D$. farina was $14.51-30.55 \mu \mathrm{g} / \mathrm{cm}^{2}$ compared to $28.10-38.95$ $\mu \mathrm{g} / \mathrm{cm}^{2}$ of DEET; and was $15.90-30.32 \mu \mathrm{g} / \mathrm{cm}^{2}$ compared to $28.51-38.42 \mu \mathrm{g} / \mathrm{cm}^{2}$ of DEET on $D$. pteronyssinus [15-17,21].

Terpeneol is a monoterpene alcohol. It is one of the active components in tea tree essential oil, Salvia lavandulifolia oil, hiba oil, basil oil, and cinnamon oil. The $\mathrm{LD}_{50}$ value of terpineol against $D$. farina was between 4.33-22.05 $\mu \mathrm{g} / \mathrm{cm}^{2}$, which was more active than DEET (28.1-37.67 $\left.\mu \mathrm{g} / \mathrm{cm}^{2}\right)$. Similar effects were found for $D$. pteronyssinus.

\subsection{Cineole}

1,8-Cineole is the most abundant ingredient in the Eucalyptus essential oil and S. lavandulifolia leaf oil. The activity of cineole on D. farina, D. pteronyssinus, 
and $T$. putrescentiae was measured by contact bioassay.

The $\mathrm{LD}_{50}$ was $12.3,12.4$, and $10.73 \mu \mathrm{g} / \mathrm{cm}^{2}$ for three dust mites, respectively, which was lower than benzyl benzoate $\left(\mathrm{LD}_{50}: 7.46,6.52,9.70 \mu \mathrm{g} / \mathrm{cm}^{2}\right)$ [12]. Other study also demonstrated the slight acaricidal effects of cineole $[17,22]$.

Table 1. The acaricidal effects of crude essential oils from different plants

\begin{tabular}{|c|c|c|c|c|c|}
\hline \multirow{2}{*}{ Essential oil } & \multicolumn{2}{|c|}{ Mite species (LD (50, 95\%CI) } & \multicolumn{2}{|c|}{ Negative control (DEET, LD50, 95\%CI) } & \multirow{2}{*}{ Reference } \\
\hline & D. farina & D. pteronyssinus & D. farina & D. pteronyssinus & \\
\hline $\begin{array}{l}\text { Melissa officinalis } \\
\text { (France) }\end{array}$ & $3.91(3.23-4.64)$ & $3.53(2.90-4.11)$ & \multirow{3}{*}{$\begin{array}{c}19.98(17.61-22.77) \\
\text { (DEET) }\end{array}$} & \multirow{3}{*}{$\begin{array}{c}14.44(12.56-16.64) \\
(\text { DEET) }\end{array}$} & \multirow{3}{*}{ [9] } \\
\hline $\begin{array}{l}\text { Melissa officinalis } \\
\text { (Ireland) }\end{array}$ & $5.29(4.44-6.27)$ & $4.97(3.67-6.41)$ & & & \\
\hline $\begin{array}{l}\text { Melissa officinalis } \\
\text { (Serbia) }\end{array}$ & $5.50(4.64-6.51)$ & $5.85(4.45-7.36)$ & & & \\
\hline S.lavandulifolia oil & $3.18(2.64-4.33)$ & $3.15(2.03-4.22)$ & - & - & [9] \\
\hline cade oil & $2.55(2.45-2.65)$ & $2.50(2.40-2.60)$ & - & - & [9] \\
\hline Hiba oil & $\begin{array}{c}126.26(106.08- \\
150.79)\end{array}$ & $\begin{array}{c}174.76(148.37- \\
211.83)\end{array}$ & $\begin{array}{c}35.53 \text { (30.61-41.61) } \\
\text { (DEET) }\end{array}$ & $\begin{array}{c}38.42 \text { (33.19-44.95) } \\
\text { (DEET) }\end{array}$ & {$[12]$} \\
\hline Basil oil & $\begin{array}{c}127.20(109.33- \\
145.39)\end{array}$ & - & $\begin{array}{c}37.67(30.11-52.92) \\
(\text { caDEET })\end{array}$ & - & {$[15]$} \\
\hline P. cattleianum & $2.44(2.35-2.55)$ & $2.4(2.30-2.50)$ & $\begin{array}{c}21.44(20.35-22.12) \\
(\text { DEET) }\end{array}$ & $\begin{array}{c}15.31(14.22-16.14) \\
\text { (DEET) }\end{array}$ & {$[16]$} \\
\hline S. barbata oil & $2.55(2.45-2.65)$ & $2.50(2.40-2.60)$ & - & - & {$[17]$} \\
\hline $\begin{array}{l}\text { Asarum sieboldii } \\
\text { Miq oil }\end{array}$ & $37.7(33.1-42.7)$ & - & $\begin{array}{c}57.9(52.3-65.2) \\
\text { (DBP) }\end{array}$ & - & {$[10]$} \\
\hline A. koreana oil & $3.53(3.40-4.69)$ & $4.15(3.43-5.10)$ & - & - & [13] \\
\hline Patchouli oil & $6.11(5.59-6.63)$ & - & $\begin{array}{c}58.52(52.32-65.19) \\
(\mathrm{DBP})\end{array}$ & - & {$[18]$} \\
\hline Horseradish oil & $1.54(1.09-2.13)$ & - & $\begin{array}{c}24.49(22.16-27.17) \\
(\mathrm{DBP})\end{array}$ & - & {$[14]$} \\
\hline C. cassia & $4.6(3.9-5.4)$ & - & $\begin{array}{c}58.52(52.3-65.2) \\
\text { (DBP) }\end{array}$ & - & [7] \\
\hline P. cablin & $6.0(5.6-6.6)$ & - & $\begin{array}{c}58.52(52.3-65.2) \\
\text { (DBP) }\end{array}$ & - & {$[20]$} \\
\hline A. sieboldii & $37.0(33.1-42.7)$ & - & $\begin{array}{c}58.52(52.3-65.2) \\
(\mathrm{DBP})\end{array}$ & - & {$[20]$} \\
\hline $\begin{array}{l}\text { E. caryophyllata } \\
\text { (petroleum ether) }\end{array}$ & $5.0(4.4-5.5)$ & - & $\begin{array}{c}58.52(52.3-65.2) \\
(\mathrm{DBP})\end{array}$ & - & {$[20]$} \\
\hline Manuka oil & $0.54(0.49-0.57)$ & $0.67(0.65-0.70)$ & $\begin{array}{c}37.12(36.12-39.25) \\
\text { (DEET) }\end{array}$ & $\begin{array}{c}18.23(17.47-19.05) \\
(\text { DEET })\end{array}$ & {$[11]$} \\
\hline C. obtusa Leaf & $23.1(22.52-23.64)$ & $20.9(20.51-21.43)$ & $\begin{array}{c}37.7(37.19-38.32) \\
\text { (DEET) }\end{array}$ & $\begin{array}{c}19.3(18.73-19.79) \\
\text { (DEET) }\end{array}$ & [19] \\
\hline Clove Bud Oil & $5.91(5.47-6.40)$ & $7.86(7.48-8.25)$ & $\begin{array}{c}37.59(34.60-40.94) \\
(\text { DEET) }\end{array}$ & $\begin{array}{c}17.98(15.08-22.77) \\
(\text { DEET })\end{array}$ & [8] \\
\hline
\end{tabular}


Table 2. Activities of essential oil on dust mites

\begin{tabular}{|c|c|c|c|}
\hline \multirow{2}{*}{ Essential oil } & \multicolumn{2}{|c|}{ Mite species (LD50 range) } & \multirow{2}{*}{ Reference } \\
\hline & D. farina & D. pteronyssinus & \\
\hline Methyleugenol & $0.94-5.82$ & 0.67 & {$[8,15,18]$} \\
\hline Eugenol & $5.47-12.52$ & 3.71 & {$[8,15,17]$} \\
\hline Isoeugenol & $5.17-36.10$ & 1.55 & {$[8,17]$} \\
\hline Acetyleugenol & 14.16 & 5.41 & [8] \\
\hline$\alpha$-caryophyllene & $0.67-25.91$ & $0.62-32.08$ & {$[10,21]$} \\
\hline$\beta$-caryophyllene & $0.91-156.24$ & $1.11-37.51$ & {$[9,10,12,17,21]$} \\
\hline $\begin{array}{l}\text { Caryophyllene } \\
\text { oxide }\end{array}$ & $0.44-36.07$ & $0.47-6.35$ & {$[9,10,15,17]$} \\
\hline Linalool & $5.15-49.40$ & $5.06-44.64$ & {$[12,17,21]$} \\
\hline Camphor & $3.81-61.93$ & $3.67-60.77$ & {$[12,15,17,21]$} \\
\hline Camphene & $>78$ & $>78$ & {$[12]$} \\
\hline Terpinen-4-ol & $14.51-30.552$ & $15.90-30.3$ & {$[15-17,21]$} \\
\hline Terpineol & $4.33-22.05$ & $4.67-25.69$ & {$[12,16,17,21]$} \\
\hline Cineole & $12.30-164.8$ & 12.4 & {$[12,17]$} \\
\hline
\end{tabular}

\section{Conclusion}

Dust mites induced diseases have led to a lot of sufferings for humans. Many drugs have been used for the treatment of the skin infections and allergies diseases caused by the dust mites. However, the problem of resistance, environmental issues linked to chemical treatment urged us to seek for new approaches. Recently, essential oils from different plants were found to be safe and effective alternatives for killing different types of mites. The crude essential oils from Melissa officinalis, S.lavandulifolia oil, cade oil, P. cattleianum, Patchouli oil, Horseradish oil, C. cassia, P. cablin, Manuka oil, Clove Bud oil, and the pure essential oils, such as eugenol, caryophyllene, and camphor might be good candidates for the dust mites.

Further studies on biological mechanisms of the acaricidal effects of these active essential oils, and the structure-activity relationships are needed to make the functions of these drugs more clear.

The present study was supported by the Hunan Provincial Key Laboratory of Fundamental and Clinical Research on Functional Nucleic Acid; the Application Characteristic Discipline of Hunan Province; Hunan Provincial Natural Science Foundation (No. 2019JJ40330); the Foundation of Hunan Educational Committee (Grant No. 19A060, 19A055).

\section{References}

1. J.E. van Bronswijk, R.N. Sinha, Pyroglyphid mites (Acari) and house dust allergy, J Allergy. 47, 31-52 (1971).

2. M.J. Colloff, Distribution and abundance of dust mites within homes, Allergy. 53, 24-27 (1998).

3. B.B. Thind, J.A. Dunn, A laboratory evaluation of a regulated airflow through wheat at four combinations of temperature and humidity on the productivity of three species of stored product mites, Exp. Appl. Acarol. 27, 89-102 (2002).

4. J. Portnoy, J.D. Miller, P.B. Williams, et al., Environmental assessment and exposure control of dust mites: a practice parameter, Ann. Allergy Asthma Immunol. 111, 465-507 (2013).

5. M.T. Muñoz-Quezada, B.A. Lucero, V.P. Iglesias, et al., Chronic exposure to organophosphate (OP) pesticides and neuropsychological functioning in farm workers: a review, Int J Occup Environ Health. 22, 68-79 (2016).

6. H.Q. Wu, L. Li, J. Li, et al., Acaricidal activity of DHEMH, derived from patchouli oil, against house dust mite, Dermatophagoides farinae, Chem. Pharm. Bull.. 60, 178-182 (2012).

7. Y.K. Yun, H.K. Kim, J.R. Kim, K. Hwang, Y.J. Ahn, Contact and fumigant toxicity of Armoracia 
rusticana essential oil, allyl isothiocyanate and related compounds to Dermatophagoides farinae, Pest Manag. Sci. 68, 788-794 (2012).

8. E.H. Kim, H.K. Kim, Y.J. Ahn, Acaricidal activity of clove bud oil compounds against Dermatophagoides farinae and Dermatophagoides pteronyssinus (Acari: Pyroglyphidae), J. Agric. Food Chem. 51, 885-889 (2003).

9. J.H. Park, H.S. Lee, Acaricidal target and mite indicator as color alteration using 3,7-dimethyl-2,6octadienal and its derivatives derived from Melissa officinalis leaves, Sci Rep. 8, 8129 (2018).

10. M.S. Oh, J.Y. Yang, M.G. Kim, H.S. Lee, Acaricidal activities of $\beta$-caryophyllene oxide and structural analogues derived from Psidium cattleianum oil against house dust mites, Pest Manag. Sci. 70, 757-762 (2014).

11. E.Y. Jeong, M.G. Kim, H.S. Lee, Acaricidal activity of triketone analogues derived from Leptospermum scoparium oil against house-dust and stored-food mites, Pest Manag. Sci. 65, 327-331(2009).

12. M.J. Lee, J.H. Park, H.S. Lee, Acaricidal toxicities and synergistic activities of Salvia lavandulifolia oil constituents against synanthropic mites, Pest Manag. Sci. 74, 2468-2479 (2018).

13. J.Y. Yang, M.G. Kim, H.S. Lee, Acaricidal toxicities of 1-hydroxynaphthalene from Scutellaria barbata and its derivatives against house dust and storage mites, Planta Med. 79, 946-951 (2013).

14. M.S. Oh, J.Y. Yang, H.S. Lee, Acaricidal toxicity of 2'-hydroxy-4'-methylacetophenone isolated from Angelicae koreana roots and structure-activity relationships of its derivatives, J. Agric. Food Chem.. 60, 3606-3611 (2012).

15. J.R. Kim, H. Perumalsamy, H.M. Shin, S.G. Lee, Y.J. Ahn, Toxicity of Juniperus oxycedrus oil constituents and related compounds and the efficacy of oil spray formulations to Dermatophagoides farinae (Acari: Pyroglyphidae), Exp. Appl. Acarol.. 73, 385-399 (2017).

16. J.R. Kim, H. Perumalsamy, M.J. Kwon, S.U. Chae, Y.J. Ahn, Toxicity of hiba oil constituents and spray formulations to American house dust mites and copra mites, Pest Manag. Sci. 71, 737-743 (2015).

17. H. Perumalsamy, J.Y. Kim, J.R. Kim, K.N. Hwang, Y.J. Ahn, Toxicity of basil oil constituents and related compounds and the efficacy of spray formulations to Dermatophagoides farinae (Acari: Pyroglyphidae), J. Med. Entomol. 51, 650-657 (2014).

18. H. Wu, J. Li, F. Zhang, L. Li, Z. Liu, Z. He, Essential oil components from Asarum sieboldii Miquel are toxic to the house dust mite Dermatophagoides farinae, Parasitol. Res. 111, 1895-1899 (2012).

19. Y.S. Jang, C.H. Lee, M.K. Kim, J.H. Kim, S.H. Lee, H.S. Lee, Acaricidal activity of active constituent isolated in Chamaecyparis obtusa leaves against
Dermatophagoides spp, J. Agric. Food Chem. 53, 1934-1937 (2005).

20. H.Q. Wu, J. Li, Z.D. He, Z.G. Liu, Acaricidal activities of traditional Chinese medicine against the house dust mite, Dermatophagoides farinae, Parasitology. 137, 975-983 (2010).

21. H.K. Kim, Y.K. Yun, Y.J. Ahn, Fumigant toxicity of cassia bark and cassia and cinnamon oil compounds to Dermatophagoides farinae and Dermatophagoides pteronyssinus (Acari: Pyroglyphidae), Exp. Appl. Acarol. 44, 1-9 (2008).

22. S. el-Z, R. Hussien, F. Saher, Z. Ahmed, Acaricidal activities of some essential oils and their monoterpenoidal constituents against house dust mite, Dermatophagoides pteronyssinus (Acari: Pyroglyphidae), J Zhejiang Univ Sci B. 7, 957-962 (2006). 